ORGANIC

LETTERS

\title{
New Bromopyrrole Alkaloid from the Marine Sponge Agelas wiedenmayeri
}

1999

Vol. 1, No. 3

$455-457$

\section{Michael Assmann, ${ }^{\dagger}$ Ellen Lichte, ${ }^{\dagger}$ Rob W. M. van Soest, ${ }^{\ddagger}$ and Matthias Köck† \\ Institut für Organische Chemie, Johann Wolfgang Goethe-Universität, \\ Marie-Curie-Strasse 11, D-60439 Frankfurt, Germany, and Instituut voor Systematiek \\ en Ecologie, Zoölogisch Museum, P.O. Box 94766, Universiteit van Amsterdam, \\ 1090 GT Amsterdam, The Netherlands}

km@org.chemie.uni-frankfurt.de

Received May 13, 1999

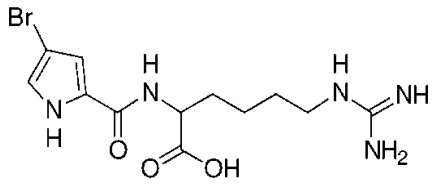

A detailed analysis of the chemical constituents of a specimen of Agelas wiedenmayeri (Alcolado, 1984) was performed. Four brominated alkaloids (1-4) were isolated and one was identified as a new bromopyrrole metabolite. The structure of the new compound, 1, was assigned using spectroscopic methods. Compounds 2 and 3, which are the major brominated metabolites, have been previously described from other Agelas sponges. The new compound, 1, may be a biosynthetic precursor for oroidin-like derivatives.

Bromopyrrole-derived alkaloids are well-known in marine sponges of the genus Agelas. ${ }^{1}$ In our search for bioactive substances from marine organisms, a series of brominated pyrrole alkaloids have been isolated from a specimen of the sponge Agelas wiedenmayeri (Alcolado, 1984) collected off the coast of the Florida Keys, FL. Examination of the methanol/dichloromethane extract of this sponge resulted in isolation of the known alkaloids 4,5-dibromopyrrole-2carboxylic acid 2, oroidin $\mathbf{3}$, and bromoageliferin $\mathbf{4}$ as well as of the new bromopyrrole-derived alkaloid, 4-bromopyrrole-2-carboxyhomoarginine 1 (5 mg, $0.005 \%$ of dry weight) (Figure 1). In this communication we describe the isolation and structural elucidation of the new bromopyrrole alkaloid 1. To the best of our knowledge, this is the first report on the chemistry of Agelas wiedenmayeri.

\footnotetext{
$\dagger$ Johann Wolfgang Goethe-Universität.

\# Universiteit van Amsterdam.

(1) (a) Braekman, J. C.; Daloze, D.; Stoller, C.; van Soest, R. W. M. Biochem. Syst. Ecol. 1992, 20, 417-431 and references therein. (b) Cafieri, F.; Carnuccio, R.; Fattorusso, E.; Taglialatela-Scafati, O.; Carnuccio, R. Bioorg. Med. Chem. Lett. 1995, 5, 799-804. (c) Cafieri, F.; Fattorusso, E.; Mangoni, A.; Taglialatela-Scafati, O. Tetrahedron 1996, 52, 13713-13720. (d) Cafieri, F.; Fattorusso, E.; Mangoni, A.; Taglialatela-Scafati, O. Tetrahedron Lett. 1996, 37, 3587-3590. (e) Cafieri, F.; Carnuccio, R.; Fattorusso, E.; Taglialatela-Scafati, O.; Vallefuoco, T. Bioorg. Med. Chem. Lett. 1997, 7, 2283-2288. (f) Cafieri, F.; Fattorusso, E.; Taglialatela-Scafati, O. J. Nat. Prod. 1998, 61, 122-125.

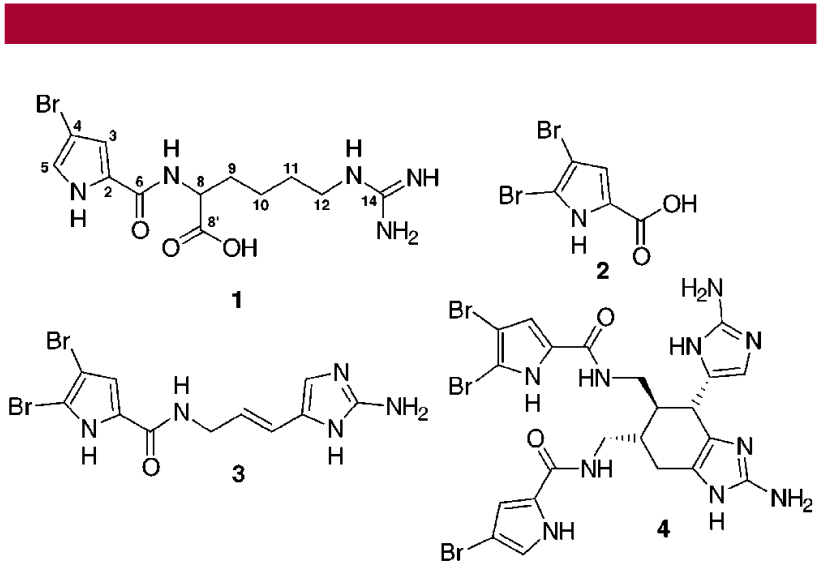

Figure 1. Secondary metabolites of Agelas wiedenmayeri.

The marine sponge Agelas wiedenmayeri (Alcolado, 1984) investigated in this study was collected in May 1998 by SCUBA diving (19 ft depth) at North Dry Rocks in the Florida Keys, FL. The specimen is composed of short, reddish, thick-walled tubes of up to $3 \mathrm{~cm}$ diameter with characteristic keyhole terminations. A voucher specimen is deposited under registration no. ZMA POR. 13505 in the 
Zoölogisch Museum, Amsterdam, The Netherlands. ${ }^{2}$ Samples of Agelas wiedenmayeri were immediately frozen after collection and kept at $-20{ }^{\circ} \mathrm{C}$ until extraction. For bulk extraction followed by isolation of brominated secondary compounds, lyophilized tissue (94.68 g) of Agelas wiedenmayeri was ground and extracted at room temperature in methanol/dichloromethane. The orange/brown-colored wet crude extract was partitioned between $n$-hexane $(3 \times 500$ $\mathrm{mL})$ and methanol $(150 \mathrm{~mL})$. The methanol extract was partitioned again between ethyl acetate $(3 \times 500 \mathrm{~mL})$ and water $(300 \mathrm{~mL})$ and finally the aqueous layer was subsequently extracted with 1-butanol $(3 \times 500 \mathrm{~mL})$. The resulting ethyl acetate $(2.7 \mathrm{~g})$ and 1-butanol $(3.2 \mathrm{~g})$ phases were purified by gel permeation chromatography on Sephadex LH-20 using methanol as eluent. Fractions containing brominated metabolites were collected and monitored by TLC $^{3}$ and detected by their UV absorbance at 254 or 366 $\mathrm{nm}$. Final purification of the isolated compounds was usually achieved by silica flash column chromatography with a mixture of chloroform/methanol/ammonia (40:20:1 v/v) as eluents. Alternatively, compounds were purified either by preparative $\mathrm{HPLC}^{4}$ or by preparative LPLC $^{5}$ using $0.1 \%$ trifluoroacetic acid with acetonitrile/water gradients. ${ }^{6}$

Four compounds $(\mathbf{1}-\mathbf{4})$ could be isolated by the described method. The brominated alkaloids 4,5-dibromopyrrole-2carboxylic acid $\mathbf{2}$, oroidin $\mathbf{3}$, and bromoageliferin $\mathbf{4}$ were identified by comparison of their spectroscopic data with those previously reported. ${ }^{7}$ The FAB mass spectrum (positive ion mode) of 1 showed prominent pseudomolecular ion peaks at $m / z 360$ and $362[\mathrm{M}+\mathrm{H}]^{+}$in the ratio $1: 1$, suggesting the presence of one bromine atom. ${ }^{8}$ The molecular formula

(2) The consistency of the specimen is firm, and the skeleton offers a well-developed rectangular reticulation of spongin fibers. Primary fibers follow a straight course over large distances, they are about $40-60 \mu \mathrm{m}$ in diameter and are cored throughout the skeleton by $2-7$ spicules in cross section. Secondary fibers connect the primaries at right angles; their diameter is on the average slightly less than that of the primaries, up to about 50 $\mu \mathrm{m}$, and they are usually uncored. Both primary and secondary fibers are irregularly echinated, in some places frequently with distances of less than $50 \mu \mathrm{m}$ between the spicules, in other places echinating spicules are rare. Meshes elongate; sizes vary $150-350 \times 50-250 \mu \mathrm{m}$; spicule sizes, 95$140 \times 4-8 \mu \mathrm{m}$, with $9-13$ whorls of spines. These data conform closely to the description of Alcolado's type.

(3) This was performed on precoated TLC plates with silica gel $60 \mathrm{~F}_{254}$ (E. Merck, Darmstadt, Germany) using the same solvent system.

(4) LiChrosorb RP-select B $(7 \mu \mathrm{m}), 25 \times 250 \mathrm{~mm}$; E. Merck, Darmstadt, Germany.

(5) Silica Reversed Phase Lobar ready-filled column, LiChroprep RP-8 (40-63 $\mu \mathrm{m})$, B-size (310-25), E. Merck, Darmstadt, Germany.

(6) For HPLC analysis, samples were injected into a HPLC system equipped with a photodiode-array detector (JASCO, Germany). Routine detection was at $280 \mathrm{~nm}$. The separation column $(4.6 \times 250 \mathrm{~mm}, 5 \mu \mathrm{m})$ was prefilled with Kromasil RP-18 (Knauer GmbH, Germany). Separation was achieved by applying a linear gradient from $20 \% \mathrm{H}_{2} \mathrm{O}$ (containing $0.1 \%$ trifluoroacetic acid) to $60 \%$ acetonitrile in $40 \mathrm{~min}$. For extraction, solvents were distilled prior to use, and gradient-grade solvents were used for chromatographic applications.

(7) (a) Forenza, S.; Minale, L.; Riccio, R.; E., F. J. Chem. Soc., Chem. Commun. 1971, 1129-1130. (b) Garcia, E. E.; Benjamin, L. E.; Fryer, R. I. J. Chem. Soc., Chem. Commun. 1973, 78-79. (c) Kobayashi, J.; Tsuda, M.; Murayama, T.; Nakamura, H.; Y., O.; Ishibashi, M.; Iwamura, M.; Ohta, T.; Nozoe, S. Tetrahedron 1990, 46, 5579-5586. (d) Keifer, P. A.; Schwartz, R. E.; Koker, M. E. S.; Hughes, R. G., Jr.; Rittschof, D.; Rinehart, K. L. J. Org. Chem. 1991, 56, 2965-2975, errata 5736, 6728. (e) Walker, R. P.; Faulkner, D. J.; van Engen, D.; Clardy, J. J. Am. Chem. Soc. 1981, 103, 6772-6773. (f) Olofson, A.; Yakushijin, K.; Horne, D. A. J. Org. Chem. 1998, 63, 5787-5790. of 1 was established as $\mathrm{C}_{12} \mathrm{H}_{19} \mathrm{BrN}_{5} \mathrm{O}_{3}$ by HR-FABMS $(\mathrm{m} / \mathrm{z}$ 362.0660, $[\mathrm{M}+\mathrm{H}]^{+}, \Delta+1.0 \mathrm{mmu}$ ) which is in accordance with the ${ }^{1} \mathrm{H}$ and ${ }^{13} \mathrm{C}$ NMR data. Table 1 summarizes the $1 \mathrm{D}$

\begin{tabular}{|c|c|c|c|c|}
\hline position & $\delta\left({ }^{13} \mathrm{C}\right)^{\mathrm{a}}$ & $\delta\left({ }^{1} \mathrm{H}\right)^{\mathrm{b}}$ & cosyc & $\mathrm{HMBC}^{\mathrm{d}}$ \\
\hline $\mathrm{N}-1$ & - & $11.84(1 \mathrm{H})$ & 5 & 3 \\
\hline$C-2$ & 126.3 & - & - & - \\
\hline$C-3$ & 112.1 & $6.99(1 \mathrm{H})$ & - & 2,5 \\
\hline C-4 & 94.9 & - & - & - \\
\hline$C-5$ & 121.4 & $7.00(1 \mathrm{H})$ & 1 & 3,4 \\
\hline C-6 & 159.5 & - & - & - \\
\hline $\mathrm{N}-7$ & - & $8.20(1 \mathrm{H})$ & 8 & $6,8,9$ \\
\hline$C-8$ & 51.6 & $4.32(1 \mathrm{H})$ & 7,9 & $6,8^{\prime}, 9,10$ \\
\hline$C-8^{\prime}$ & 173.6 & - & - & - \\
\hline$C-9$ & 30.3 & $1.71(2 \mathrm{H})$ & 8,10 & $8,8^{\prime}, 10,11$ \\
\hline C-10 & 22.9 & $1.36(2 \mathrm{H})$ & 9 & - \\
\hline$C-11$ & 28.0 & $1.48(2 \mathrm{H})$ & 12 & 10,12 \\
\hline C-12 & 40.7 & $3.09(2 \mathrm{H})$ & 11,13 & $10,11,14$ \\
\hline $\mathrm{N}-13$ & - & $7.55(1 \mathrm{H})$ & 12 & 11,12 \\
\hline C-14 & 156.6 & - & - & - \\
\hline
\end{tabular}

${ }^{a}{ }^{1} \mathrm{H}$ chemical shifts are referenced to the DMSO- $d_{6}$ signal $(2.50 \mathrm{ppm})$. ${ }^{b}{ }^{13} \mathrm{C}$ chemical shifts are referenced to the DMSO- $d_{6}$ signal $(39.5 \mathrm{ppm})$. ${ }^{c}$ The COSY correlations are given for both sides of the diagonal. ${ }^{d}$ The HMBC correlations are given from protons to carbons. Further correlations were observed but not used because of a low signal-to-noise ratio or unambiguous assignment. These correlations are not given in the table and were not used in the Cocon calculations (H-1 to C-4, H-10 to C-11, and H-11 to C-9).

and 2D NMR data of $\mathbf{1}$. The 4-bromopyrrole-2-carboxamide moiety was strongly indicated by the signals at $\delta 6.99(\mathrm{H}-$ $3)$ and $\delta 7.00(\mathrm{H}-5)$ in the ${ }^{1} \mathrm{H}$ NMR spectrum (DMSO- $\left.d_{6}\right)$ and by the ${ }^{13} \mathrm{C}$ NMR pattern of resonances $\left(\delta_{\mathrm{C}} 126.3, \mathrm{C}-2\right.$; $\left.\delta_{\mathrm{C}} 112.1, \mathrm{C}-3 ; \delta_{\mathrm{C}} 94.9, \mathrm{C}-4 ; \delta_{\mathrm{C}} 121.4, \mathrm{C}-5 ; \delta_{\mathrm{C}} 159.5, \mathrm{C}-6\right)$, which appeared very similar to the values reported in the literature for other Agelas bromopyrrole alkaloids. ${ }^{\text {1c,7d }}$ The presence of the pyrrole part was also supported by the UV absorption $\left(\mathrm{H}_{2} \mathrm{O}\right)$ at $\lambda_{\max } 271 \mathrm{~nm}(\epsilon 11500)$, which is typical for 2-carboxamide-substituted pyrrole chromophores. ${ }^{10}$ Furthermore, the ${ }^{13} \mathrm{C}$ NMR data showed characteristic resonances due to four $\mathrm{sp}^{3}$ methylenes at $\delta_{\mathrm{C}} 40.7,30.3,28.0$, and 22.9 and two $\mathrm{sp}^{2}$ quaternary carbons at $\delta_{\mathrm{C}} 156.6$ and 173.6. The $\mathrm{sp}^{2}$ carbon chemical shift $(\mathrm{C}-14)$ at $\delta_{\mathrm{C}} 156.6 \mathrm{ppm}$ implied the presence of a guanidino group. This was

(8) Mass spectral analysis (HRFAB-MS) was performed on a JEOL JMS700 sector-field mass spectrometer with 3-nitrobenzyl alcohol (NBA) as matrix

(9) ${ }^{1} \mathrm{H}$ NMR and ${ }^{13} \mathrm{C}$ NMR spectra were recorded on Bruker AM 250, AMX400 and DRX600 NMR spectrometers. A 5-mg sample of 1 in 0.5 mL DMSO- $d_{6}$ was used for the NMR measurements. All NMR experiments were measured at $300 \mathrm{~K}$. The DQF- ${ }^{1} \mathrm{H},{ }^{1} \mathrm{H}$-COSY and the ${ }^{1} \mathrm{H},{ }^{13} \mathrm{C}-\mathrm{HSQC}$ experiment were carried out with standard parameters. The ${ }^{1} \mathrm{H},{ }^{13} \mathrm{C}-\mathrm{HMBC}$ experiment was acquired with 4096 data points in $F_{2}$ (acquisition time 228 $\mathrm{ms}), 256$ increments, and 128 acquisitions. The delay for evolution of the heteronuclear long-range couplings was set to $80 \mathrm{~ms}$ and the relaxation delay to $1.8 \mathrm{~s}$. The pulse programs were used from the Bruker library.

(10) Jaffe, H. H.; Orchin, M. Theory and Application of UV Spectroscopy; Wiley: New York, 1962; pp 350-351. UV/vis spectra were obtained in $\mathrm{H}_{2} \mathrm{O}$ using a Perkin-Elmer UV/vis spectrometer Lambda 16. 
confirmed by a positive coloration in the Sakaguchi test. ${ }^{11}$ The signal at $\delta_{\mathrm{C}} 173.6 \mathrm{ppm}$ was attributed to a carboxylate group, further supported by the IR $(\mathrm{KBr})$ absorption band at $v_{\max } 1676 \mathrm{~cm}^{-1} .^{12}$

In order to evaluate the correctness of the proposed structure 1, a COCON calculation ${ }^{13}$ with the experimental data (12 $\mathrm{COSY}^{14}$ and $23 \mathrm{HMBC}^{15}$ correlations) was carried out. The bonds of the guanidino group were set fixed due to the positive Sakaguchi test. CoCON generated 20 possible structures, containing the homoarginine substructure. For all structural proposals a ${ }^{13} \mathrm{C}$ chemical shift calculation was carried out using SpecEdit. ${ }^{16}$ The best proposal had a 2,3substitution pattern of the pyrrole which is not in accordance with the COSY data because no correlation was obtained between $\mathrm{H}-3$ and $\mathrm{H}-5$. One COSY correlation in the homoarginine part was not obtained experimentally (H-10 to $\mathrm{H}-11)$. Since this part is fixed due to the HMBC correlations it was predefined and the CoCON calculations were repeated with the option that all bonds between two protonated carbons were forbidden if no COSY correlation was observed. With this restriction CoCON generated four possible structures (Figure 2).
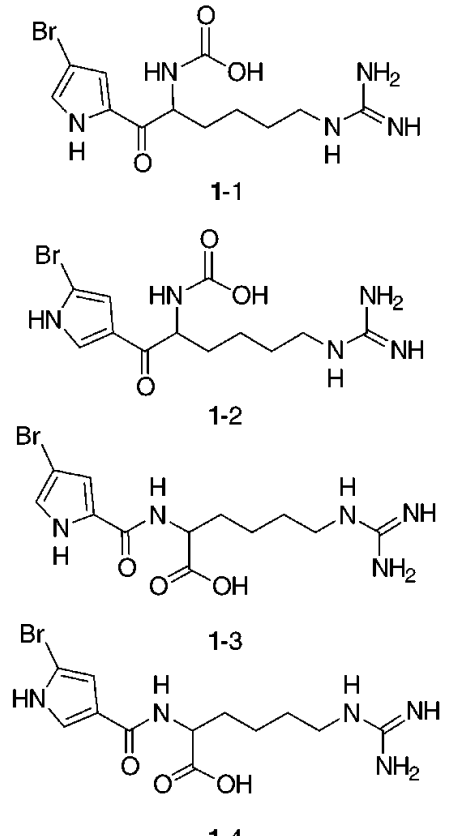

$1-4$

Figure 2. Structural proposals of $\mathbf{1}$ generated by Cocon.
In structures 1-1 (averaged ${ }^{13} \mathrm{C}$ chemical shift deviation over all carbon atoms calculated with SpecEdit $\left\langle\Delta \delta\left({ }^{13} \mathrm{C}\right)\right\rangle$ $=4.0 \mathrm{ppm})$ and 1-2 (7.9 ppm) the $\mathrm{NH}$ and the $\mathrm{C}^{\alpha}$ of the homoarginine part are exchanged in contrast to structures 1-3 (3.7 ppm) and 1-4 (6.2 ppm). In structures 1-1 and 1-3 the pyrrole substituents are exchanged in comparison to structures 1-2 and 1-4. This has a more dramatic effect on the averaged ${ }^{13} \mathrm{C}$ chemical shift deviations than the exchange of $\mathrm{NH}$ and $\mathrm{C}^{\alpha}$. The structures 1-1 and 1-2 can be excluded because these are carbamic acids which are not stable under laboratory conditions. The structural proposal 1-3 is favored by its chemical deviations obtained by SpecEdit calculations and thus supposed to be the correct constitution.

Compound $\mathbf{1}$ is a condensation product of 4-bromopyrrole2-carboxylic acid and homoarginine. This compound is of interest because it does not correspond to the proposed biosynthesis of the oroidin-like alkaloids. The hypothetical biosynthetic pathway is based on the formation of an amide bond between a pyrrole-2-carboxylic acid precursor and an aminopropylimidazole moiety which are both derived from ornithine. ${ }^{1 \mathrm{a}}$ Therefore, compound $\mathbf{1}$ may be alternatively a biosynthetic precursor of hymenidin/oroidin-related alkaloids in sponges of the genus Agelas. Further investigations of the biosynthesis must validate this hypothesis.

Acknowledgment. Financial support from the Deutsche Forschungsgemeinschaft (Ko 1314/3-1 to 3-4) is gratefully acknowledged. Furthermore, we thank Professor Joseph R. Pawlik (Department of Biological Sciences, University of North Carolina Wilmington, NC) for giving M.A. the opportunity to participate in a scientific sojourns to the Florida Keys in May 1998, during which the sponge Agelas wiedenmayeri was collected. We thank the staff of the National Undersea Research Center (NURC) at Key Largo, FL, for their cooperation. Finally, we acknowledge the support of Professor Dr. Christian Griesinger.

\section{OL990664H}

(11) (a) Hessing, A.; Hoppe, K. Chem. Ber. 1967, 100, 3649-3654. (b) Auterhoff, H.; Kovar, K.-A. Identifizierung von Arzneistoffen, 3th ed.; Wissenschaftliche Verlagsgesellschaft $\mathrm{mbH}$ : Stuttgart, 1977.

(12) (a) IR (KBr) spectra were recorded on a Perkin-Elmer 1600 Series FT-IR spectrometer. IR (KBr) of 1: $v_{\max } 3406,3194,1676,1637,1523$, $1385,1205,1136 \mathrm{~cm}^{-1}$. (b) Hesse, M.; Meier, H.; Zeeh, B. Spectroscopic Methods in Organic Chemistry; Georg Thieme Verlag: Stuttgart, 1997.

(13) (a) Lindel, T.; Junker, J ; Köck, M. J. Mol. Model. 1997, 3, 364368. (b) Lindel, T.; Junker, J.; Köck, M. Eur. J. Org. Chem. 1999, 573577. (c) Köck, M.; Junker, J.; Maier, W.; Will, M.; Lindel, T. Eur. J. Org. Chem. 1999, 579-586.

(14) Aue, W. P.; Bartholdi, E.; Ernst, R. R. J. Chem. Phys. 1976, 64 , 2229-2246.

(15) Bax, A.; Summers, M. F. J. Am. Chem. Soc. 1986, 108, 20932094.

(16) Maier, W. In Computer - Enhanced Analytical Spectroscopy; Wilkens, C. L., Ed.; Plenum Press: New York, 1993; Vol. 4, pp 37-55. 